\title{
Structured instrument design
}

\author{
P.H. Sydenham \\ School of Electronic Engineering - Measurement and Instrumentation Systems, South Australian Institute of Technology, Adelaide South \\ Australia
}

This is a reissue of a paper which appeared in ACTA IMEKO 1988, Proceedings of the $11^{\text {th }}$ Triennial World Congress of the International Measurement Confederation (IMEKO), "Instrumentation for the 21st century", 16-21.10.1988, Houston, pp. 271-275.

The overall system design of measuring instrumentation is currently carried out by an intuitive process. Using a "required plus available" knowledge approach, implemented in computers, the user's domain can be interfaced to measurement engineering expertise providing an effective CAE tool. Progress in this new approach, that promises to dramatically reduce design time, place system generation in the hands of application domain users, and bring about more unity in measurement scholarship, is reviewed.

\section{Section: RESEARCH PAPER}

Keywords: measurement theory, value, error, uncertainty

Citation: P.H. Sydenham, Structured instrument design, Acta IMEKO, vol. 3, no. 1, article 9, May 2014, identifier: IMEKO-ACTA-03 (2014)-01-09

Editor: Luca Mari, Università Carlo Cattaneo

Received May $1^{\text {st }}, 2014$; In final form May $1^{\text {st }}, 2014$; Published May 2014

Copyright: (C) 2014 IMEKO. This is an open-access article distributed under the terms of the Creative Commons Attribution 3.0 License, which permits unrestricted use, distribution, and reproduction in any medium, provided the original author and source are credited

\section{NEED FOR MORE FUNDAMENTAL APPROACH}

The need for measuring instruments arises in application domains. An instrument forms the link to observed processes for gathering knowledge about that process.

Application domain persons are those who know best about the knowledge sought but often do not have sufficient background to efficiently design instrument systems. Experienced instrument designers, in contrast, have the design expertise but need to become familiar with the application domain knowledge to provide worthwhile support.

This mismatch of knowledge requirement has resulted in haphazard improvement in instrument design and application. There has been too much reinvention and too little systematic building upon work of others.

The overall approach to the design of instruments, and related electronics, has never been streamlined since its sophistication began around the 1920's. Ref. [1] provides an historical overview of the developments. Study of past general catalogue style texts on measuring technology show that whilst the form of implementation is changing the basic fundamentals are relatively static.

The need for improved methodology and practice is increasing as measuring system performance and the cost and time to produce them come under closer scrutiny. It is now becoming clear that this inherited, uncoordinated, methodology can be improved by integrating the core knowledge of what has been learned over this past half century.
Available computing technology and software techniques, the mature state of recorded knowledge about measurement systems theory and practice sets the scene for revising the approach to the development and application of measuring systems.

This paper provides an overview of work of the Measurement and Instrumentation Systems Centre MISC in this regard placing that contribution in perspective with other related work.

\section{SENSORY INTERFACES TO THE PHYSICAL WORLD}

There has been much identified and well supported activity for fundamental research into the design and application of the human to computer interface, HCI.

In contrast it has been most difficult to gain respectability for counterpart work into the physical world to computer interface PWCI - the interface that provides people and hence, also computer systems, with knowledge about the world in which we exist. The PWCI is a sensory interface [2] established with a properly designed and installed measurement system.

A measuring instrument is equally as much an information machine, as is a computer. This concept has been cursorily developed by Finkelstein, another "fundamental issues" contributor [3, 4], and was a prime realisation of the historical study [1], being reflected in its title. Measurement systems are the "Cinderella" of the Information Technology movement.

The research programme of MISC concentrates on development of universally applicable sensory interfacing 
concepts. It is strengthened by working in close co-operation with the Loughborough University of Technology, Computer Human Interface Centre, LUTCHI and the CAD of instruments Group of the City University, London.

Research activities into the PWCI and the HCI must be integrated to ensure that humans, computers and the physical world each are interfaced with respect to the common entity all need, that is, knowledge. This concept has been expanded in [5].

\section{KEY STAGES IN INSTRUMENT DESIGN}

Design or selection of a suitable instrument system has identifiable serial steps. Each step should progressively better interface the necessary application domain knowledge to the instrument design expertise base as neither knows enough of the other at the various points of that process.

The instrument design task is, fortunately, not as diverse as its manifestation and varied forms have made it appear. The process of working from a "knowledge needed" statement through to installed hardware is not over complex once the necessary information and procedural path are clarified and adopted in a systematic, constrained and pragmatic manner.

The design of measurement systems should begin firmly embedded in terms of the knowledge needed from the sensory interface to be created by the designer who is most likely to be a user.

A strategy to assist applications persons develop rigorous operational and technical design specifications has been developed [6] and it is being implemented as software under the name, Measurement Interface Design System, MINDS. This step helps set up the vital metrological requirement in terms of measurands, their key metrology parameter values, influence variables and how the several measurands' information is to be combined to form the "many to fewer" mapping process needed in the sensory interface.

A means to convert the output of MINDS into an engineering specification document, or to directly write a specification where it is already known what measurement system measurand is needed, has been developed as software called SPECRITER [7]. This stage calls for more knowledge about non-metrological aspects of a real instrument examples being, packaging, environment, testing, power supplies, cooling, and mass.

Having developed a sound specification it can be used to either purchase a ready-made item, have it designed and manufactured or use it as basic knowledge for the next step of the MISC designer system which provides core sensor design shells.

The purchase of proprietary items is not being studied in the MISC programme because of the existence of an extensive project that already exists at the Warren Springs Laboratory, UK.

Their THESAC Centre is developing an on-line, dial-up, knowledge based, service whereby users can rapidly learn which proprietary sensors come close to their need. Although that programme is targeted at the process industry the over 70 measurands catered for are applicable to other applications.

More adequate understanding of the taxonomy of information systems, formed as instruments and electronic systems, is now becoming essential.

This has become a key necessity in a MISC venture [8] investigating automatic electronic system design software that can be used by applications persons not having electronic training.

Before that process can be automated a classification of electronic building blocks formed in terms of a knowledge and information role was needed. At present designers use heuristic knowledge, in an art form manner, to decide which block to use and where. The names and concepts used go back to the 1930 's, well before information technology was recognised as a major entity.

At the sensor design shell level a key taxonomy consideration now is which shells to develop and whether there exists a generic building block approach that can be used in a hierarchical manner. To build a shell for every measurand known would appear to be the wrong way to proceed. The MISC project currently has length, pressure and temperature shells in development along with other foregoing shells exploring how these shells can cover their use for measurement of other variables. The shells provide extensive engineering documentation to support manufacture.

Having the appropriate sensor systems and knowledge about how their signals should be combined is still not the end of the applications domain users task. Installation, commissioning and operation also require assistance.

The MISC programme framework also has projects in place to develop these aspects by incorporating heuristic and formal knowledge into software and hardware. These will tell the user how to install the sensors, automatically test and set them up (with some help from the user), and then automatically run the system with regular operational health checks.

The overall programme aims to take sensory system design into a new era providing do-it-yourself capability [9].

Counterpart work by others touches on some facets of the commissioning and use step. Distributed sensory systems are currently a more widespread research interest, the work of Brignell, University of Southampton, being an example. Smart sensors are studied by several of the silicon sensor develop teams. MISC has the work of Haskard to call upon [10].

At this early stage it is already clear that the CAEINST software system now needs extension to cater for systems of sensors. Work in 1988 covers setting up interfaces between CAEINST designed sensors and manufacturing and scientific computers and of a data logger arrangement.

A review of the project has recently been prepared that gives more detail of individual projects [11].

This, now several year long experience, permits some general conclusions to be given about CAD of instruments.

\section{USING COMPUTERS TO ASSIST DESIGN}

Knowledge based systems allied to traditional formal knowledge are essential to develop application user driven designer systems. To provide CAD tools based only in formal description modelling is to throw away the powerful rules of thumb that are used so effectively in practice to get fast, adequate results.

The place for rigorous modelling is in assisting in-depth development needed to squeeze more out of a given design form, such as in a major product line situation or where the mathematical approach is superior to the heuristic way, for example to calculate the thickness of a pressure gauge diaphragm.

The exemplary formal transducer modelling work of the City University, London, has been supported by manufacturers wishing to improve their products. MISC has incorporated a 
simple version of their MEDIEM modelling software into its temperature sensor shell [12] to calculate thermal parameters and response times of the thermowell protected sensor.

Much of sensory system design needs are not for enhanced modelling elegance but are in the more subjective aspects such as, selection of appropriate device, management of the design process, awareness of standards, terminology and other semantic fields for such aspects as costing and quality.

Although the best computational methodology for implementing the above concept is not yet clear, the benefits of using the software based design approach are already emerging.

Once developed the method becomes very low cost to use and to maintain. The necessary knowledge is not so fast moving as might be thought. Basic considerations will remain the same for many years.

The speed at which a user can be in possession of a good sensory system design, including full manufacturing detail, will reduce from months to days. The limiting factor for a "oneoff" task now appears to be the time to manufacture the system, not to develop its design. Work on computer integrated manufacture will improve that aspect.

It is also becoming clear that the knowledge bases needed for this field are reasonably small - a few hundred words and a hundred or so rules will often be sufficient to design a major aspect of a need. The computing task should not blow out to one concerning such breadth as parsing of English language in its totality.

\section{EFFORT NEEDED, PROBLEMS OF BEING PIONEERS}

As already alluded to above, gaining acceptance that fundamental development in measurement science and instrument engineering is both possible and worthwhile is not easy.

As this is a radical change in both method and attitude it needs resourcing support of centralised governmental kind. It is too early to expect commercial support and its nature, being of advantage to many persons in many places yet not in large identified groups, makes support from users unlikely until it is ready to use.

At what stage this concept will be taken up by others is not clear. MISC has difficulty in citing the contribution of others to the overall systems approach because there appears to be little other work to report.

To assist software dissemination, and hopefully gain constructive criticism and faster development, MISC software is being made available to others interested in making and a contribution to the method.

Momentum will gradually develop and using this opportunity it is hoped more people will work together to move to the new methods. That will be hard decision for many as those who enter this field at this early stage will face lack of appreciation by others who cannot see that the current ways can be bettered.

\section{HORIZONS OPENED UP ONCE INSTRUMENT CAE IN USE}

To complete this review it is worth considering where the approach leads to once established.
Given that a series of, knowledge based, questions and answers can yield the full design of a sensory interface the idea can be extended to ask how many of those questions can the sensory interface resolve for itself given a sufficiently large and appropriate knowledge base and sensory system of its own.

This concept may sound like a science-fiction scenario but already worthwhile applications appear possible.

A MISC project is developing a listening sensory interface that will work out the heuristic rules of a sound enabling recognition of indicated sounds that it should, in future, discern. These rules, currently used manually (but in future possibly used by the automatic electronic system designer), have been used to build a simple analogue/digital circuit that provides the sensory mapping needed by a rule based, rather than, formal processing, method.

Thus the concept of using information machines to generate the full manufacturable design of other information machines now appears to be viable.

This theme is soon to be explored in more general manner using a sensory head having hearing and vision sensors. There the aim is to reach the highest possible programming level, that is, spoken conversation between the operator and the inspection head as the latter sits in its workplace.

Self repairing and adaptive sensory systems will also become closer because sensory systems will be able to decide if their own sensor and electronics design needs have changed and switch parts as needed without operator help.

Such visionary concepts are not new but sensory interface development based in heuristic and formal knowledge embedded in computers does provide the closest yet chance of building economically viable systems.

\section{REFERENCES}

[1] P.H. Sydenham, Measuring instruments: tools of knowledge and control, Peregrinus, Stevenage, 1979.

[2] P.H. Sydenham, Computer aided engineering of measuring instrument systems, CAE Jnl., 4 (1987) pp.117-123.

[3] L. Finkelstein, Instrument science series: introductory article, J. Phys. E. :Sci. Instrum., 10 (1977), pp.566-572.

[4] L. Finkelstein, Instrumentation, control and information technology, J.Phys.E.:Sci.Instrum., 19 (1986), pp.246-247.

[5] P.H. Sydenham, Computer aided engineering of sensing interfaces, abstract. Proc. Conf, EUROSENSORS, Cambridge, Sep. 1987.

[6] P.H. Sydenham, Structured understanding of the measurement process, Measurement, 3 (1985), pp. 115-120 and pp. 161-168.

[7] S. Cook, Automatic generation of measuring instrument specifications, Measurement, 6 (1988), pp.155-160.

[8] L.C. Jain, P.H. Sydenham, CAENIC-user-characterised, electronic systems development software, CAE Jnl., 5 (1988), pp.200-205.

[9] P.H. Sydenham, A. Skinner, R.W. Beijer, Do it yourself measurement and control CAE package, Jnl. Meas. Contr., 21 (1988), pp.69-75.

[10] M.R. Haskard, General purpose intelligent sensors, Microelectronics Jnl., 17 (1986), pp.9-14.

[11] P.H. Sydenham, CAE of instrument and electronic systems Proc. Conf. "Control '88", Christchurch, New Zealand, May, 1988.

[12] P.H. Sydenham, N.A. Morgan, M. Anfiteatro, Thermocouple temperature sensors CAD tool, CAE Jnl., 5 (1988), pp.206-210. 